\title{
NORUS
}

ISSN: $2318-1966$

v. 4 , n. 6

jul - dez 2016

Dossiê

\section{A RELAÇÃO ENTRE RURAL E URBANO NA ÓTICA DE HENRI LEFEBVRE: UM ESTUDO SOBRE O PAPEL DAS TRÍADES LEFEBVRIANAS NA CONFIGURAÇÃO ESPACIAL CONTEMPORÂNEA}

\author{
Maiara Tavares Sodré ${ }^{1}$ \\ Mestre em Geografia pela Universidade Federal do Rio Grande (FURG) \\ Solismar Fraga Martins ${ }^{2}$ \\ Professor do Instituto de Ciências Humanas e da Informação (ICHI - FURG)
}

\begin{abstract}
RESUMO
O objetivo deste artigo consiste em dissipar erros de interpretação que eventualmente cercam a proposta de Henri Lefebvre no que concerne à relação rural-urbano. Para tanto, parte-se de uma abordagem ampla sobre a perspectiva de análise lefèbvriana para a temática supracitada, utilizando-se na sequência duas tríades analíticas presentes na obra do autor para exemplificar de forma mais clara o caráter da relação rural-urbano em sua obra. As tríades eleitas consistem em: espaço absoluto, espaço abstrato e espaço diferencial; e representações do espaço, espaços de representação e prática espacial. Entende-se que, para Lefebvre, a partir de um determinado momento histórico, a lógica de organização socioprodutiva e cultural do campo deixa de seguir sua coerência interna para se submeter às imposições organizacionais emanadas da cidade. Nesse sentido, não se trata do fim do rural, mas sim da sua subordinação a um modo de vida que, mais do que urbano, torna-se, progressivamente, global.
\end{abstract}

Palavras-Chave: Henri Lefebvre; Urbano; Rural; Tríades.

\section{THE RELATION BETWEEN RURAL AND URBAN BASED ON HENRI LEFEBVRE'S APPROACH: A LEFÈBVRIAN TRIADS STUDY REGARDING THE STRUCTURE OF A CONTEMPORANEOUS AREA}

\begin{abstract}
The aim of this project is to investigate interpretations errors surrounding Henri Lefebvre's proposal concerning the rural-urban relation, and afterwards dissipate them. Altogether, it is

\footnotetext{
${ }^{1}$ Foi bolsista FAPERGS/CAPES. Integrante dos grupos de pesquisa/CNPq Estudos Agrários e Ambientais (UFPel); Território, desenvolvimento e agricultura (USP); e Núcleo de estudos regionais e agrários (UFSM). Membro da Rede de Estudos Agrários - REA Brasil, composta por grupos de pesquisa da UFPel, UNESP Rio Claro, UNIFAL e UNIMONTES.

${ }^{2}$ Mestrado em Educação Ambiental pela FURG (1997) e Doutorado em Geografia pela Universidade Federal de Santa Catarina (Área de Concentração: Desenvolvimento Regional e Urbano/2004). Tem experiência na área de Geografia, com ênfase em Geografia Urbana, Planejamento Urbano e Geografia Regional. É Coordenador do
} Programa de Pós-Graduação em Geografia (FURG).
\end{abstract}


necessary an extensive perspective approach on the Lefèbvrian investigation, using a sequence of two analytical triads presented in the author's work, therefore to illustrate more clearly the feature of this relation. The triads selected were: an absolute area, an abstract area and a differential area; and also its representation and practice. For Lefebvre, it is understood that, since a historical moment is settle, the logic of a social productive and cultural organization in the countryside no longer follows its internal coherence to cave in into organizations impositions emanated from the city. In essence, it is not about the end of the rural, but of its subordination of a life style, which it is more than urban, it is progressively global.

Keywords: Henri Lefebvre; Urban; Rural; Triads.

\section{Introdução}

A obra de Henri Lefebvre vem sendo redescoberta nos últimos anos pelas Ciências Humanas. Na Geografia, a retomada dos escritos desse autor deve bastante à inspiração da análise espacial realizada por diferentes geógrafos brasileiros que utilizaram e utilizam Lefebvre como referência na análise da produção do espaço no que tange à relação ruralurbano e à própria Sociedade Urbana. Entrementes, essa recuperação das proposições lefèbvrianas não impede que alguns pontos permaneçam enevoados, favorecendo entendimentos distorcidos das ideias do autor. Um desses pontos concerne à compreensão de Lefebvre sobre a relação entre rural e urbano e acerca do destino do rural na sociedade contemporânea. O objetivo deste artigo radica justamente na tentativa de dissipar equívocos de interpretação que cercam a proposta do autor para o desenrolar das relações rural-urbano e campo-cidade.

É comum no debate acadêmico a análise dos limites da Sociedade Urbana proposta por Lefebvre e defendida pelos geógrafos urbanos em contraposição a outras interpretações, como se fosse possível a abstração de um dos campos do conhecimento - nesse caso, o rural a partir da equivocada interpretação da teoria lefèbvriana. Em contraste com esse entendimento e tendo em vista o objetivo indicado, parte-se de uma abordagem ampla sobre a perspectiva de análise lefèbvriana para a temática supracitada, utilizando-se, na sequência, algumas das tríades analíticas presentes na obra do autor para exemplificar de forma mais clara o caráter da relação focalizada na primeira seção conseguinte a essa introdução. As tríades eleitas consistem em: espaço absoluto, espaço abstrato e espaço diferencial; e representações do espaço, espaços de representação e prática espacial. Evidentemente, outras análises de igual importância poderiam ser selecionadas, como ordem próxima e ordem distante; forma, estrutura e função; espaço vivido, espaço percebido e espaço concebido; ou reprodução biológica, reprodução da força de trabalho e reprodução das relações sociais. A 


\section{A relação entre rural e urbano na ótica de Henri Lefèbvre}

escolha das duas tríades acima referidas tem por critério de seleção a compreensão de que consistem nas que melhor representam a dinâmica da relação rural-urbano na dimensão defendida por Lefebvre.

\section{A relação rural-urbano sob o enfoque lefèbvriano}

Para abordar o entendimento de Lefebvre sobre a relação entre rural e urbano, é mister estabelecer primeiro de que forma se dá a relação campo-cidade. Para isso, por sua vez, é indispensável que se analise como se diferenciam esses dois pares analógicos referidos. Lefebvre (2006) salienta que a cidade envolve certa materialidade e vincula-se especialmente ao momento coevo, trata-se de um conceito cercado de maior concretude, existindo certa correspondência visual entre seu sentido e sua apreensão na realidade. Já o urbano consiste antes em um conjunto relações estruturadas cognitivamente e extrapoladas para a realidade palpável; o urbano implica, portanto, em um modo de vida que se projeta sobre a cidade mas não exclusivamente sobre ela, como se verá na sequência. Apesar de se mostrar mais abstrato, o urbano não dispensa uma materialidade e, sem ela, está fadado ao desaparecimento, pois não se configura como um ente de existência autônoma.

Essa mesma diferenciação se aplica ao par campo-rural, o primeiro mostrando-se mais tangível e fisicamente identificável, enquanto o segundo corresponde mais à ideia de um conjunto de relações sociais compartilhadas. Aqui também cabe a ressalva anterior: do mesmo modo que o urbano hoje não se restringe à cidade, o rural um dia já suplantou os limites do campo. Não cabe postergar esta assertiva, de modo inverso, explicitá-la agora facilitará o seu desenvolvimento: para Lefebvre, a partir de um determinado momento histórico, a lógica de organização socioprodutiva e cultural do campo deixa de seguir sua coerência interna para se submeter às imposições organizacionais emanadas da cidade. Nesse sentido, não se trata do fim do rural, mas sim da sua subordinação a um modo de vida que, mais do que urbano, torna-se, progressivamente, global.

Lefebvre (1999b) denomina como sociedade urbana ou pós-industrial esse novo modo de vida que começa a delinear-se ainda muito cedo na história da sociedade moderna, mas, antes de localizar o surgimento desse processo na escala temporal, compete ainda destacar que:

Aqui, reservaremos o termo 'sociedade urbana' à sociedade que nasce da industrialização. Essas palavras designam, portanto, a sociedade constituída por esse processo que domina e absorve a produção agrícola. Essa sociedade urbana só pode ser concebida ao final de um processo no curso do qual explodem as antigas formas 
NORUS - v4, n.6, jul - dez 2016.

urbanas, herdadas de transformações descontínuas (LEFEBVRE, 1999b, p. 15, grifos do autor).

Existe uma linha temporal na qual o surgimento da sociedade urbana pode ser inscrito. Essa linha parte da cidade política, representada pelos exemplares de cidades encontradas na Grécia e em Roma. São cidades essencialmente administrativas, não consistem em espaços de produção, pois a produção ainda se dá no campo. A cidade política nasce como corolário do rural, orienta-se a partir de lógicas advindas da agricultura e do campo. Já no final da Idade Média, com o desenvolvimento do comércio e a partir da formação dos primeiros burgos, começa a delinear-se a cidade mercantil, inicialmente ainda subjugada à lógica agrária, mas já apresentando sinais de desprendimento (LEFEBVRE, 1999a).

Lefebvre (2000) destaca que é entre os séculos XV e XVI que o rural - a terra - passa a sucumbir perante a riqueza móvel - o capital e o dinheiro - como lógica dominante, submetendo-se ao ímpeto urbanizador crescente da sociedade. Porém, não há uma data específica no calendário que marque isso, já que se trata de um movimento que inicia e se desenvolve lentamente, alterando de maneira gradativa o modo de produção e de organização daquela sociedade existente e pré-capitalista. É nesse momento, segundo o autor, que o dinheiro começa a dar sinais de superação da terra como riqueza, o que se consolidará mais tarde, quando se torna a moeda padrão. A própria terra passa ser valorada por meio do dinheiro, e a cidade se desvencilha do rural, passando a controlá-lo.

Entretanto, a linha temporal ora delineada não se esgota no momento em que sofre essa drástica ruptura, a Revolução Industrial anuncia a insurgência da cidade industrial, orientada e organizada para o atendimento das demandas industriais. Se, na visão do autor, o espaço do comércio ainda não era o espaço de produção, com a indústria e a partir dela, a cidade passa, lenta e gradativamente, a suplantar a lógica agrária tornando-se o espaço de produção por excelência e sujeitando o campo a sua lógica produtiva. Num correr do tempo, chegaríamos ao momento, pós-fase crítica, em que teríamos a completa sujeição do agrário a uma ordem global (industrial e urbana) que dirige a sociedade de forma geral, independentemente de sua localização no espaço rural ou urbano. A sociedade urbana é, contudo, apenas um horizonte, sua efetivação completa ainda não se realizou; apesar de estarmos já nos precipitando sobre o seu limiar, a subordinação do rural ao urbano apenas anuncia a conformação de uma sociedade que prioriza a lógica urbana não em oposição à rural, mas sim como representante da exacerbação da lógica capitalista de produção. 


\title{
A relação entre rural e urbano na ótica de Henri Lefèbvre
}

É a esse processo de fim do protagonismo da oposição entre campo e cidade que se refere Lefebvre (1999a), retornando a Marx:

\begin{abstract}
A contradição cidade-campo, durante um longo período (das origens à formação da burguesia, à predominância do capital comercial e da manufatura), foi uma contradição profunda, principal, essencial, para um número considerável de sociedades históricas, isto é, mortas apesar de seu esplendor. Continua sendo a contradição principal durante a ascensão do capitalismo? Certamente não, segundo Marx. Ela se subordina a outras contradições e, particularmente, às que nascem da relação de produção: capital-salário, isto é, à mais-valia, à sua formação, como à sua distribuição, e consequientemente às contradições de classes (LEFEBVRE, 1999a, p. 109, grifo do autor).
\end{abstract}

Para Fontoura (2011), esse grande processo de transformação da realidade por meio de instâncias institucionalizadas ou não pelo sistema capitalista é cognominado por Lefebvre como revolução urbana. Fontoura (2011) entende que a revolução urbana traz consigo um projeto de planificação social pelo capital que implica na criação de demandas artificialmente forjadas que se projetam sobre o campo demovendo muitas de suas estruturas tradicionais. A modernização da agricultura, entendida como o processo de difusão de insumos químicos e biológicos, bem como o uso mais disseminado de maquinário industrial são exemplos dessa situação. Desse modo, cada vez mais a população residente no rural vê seu orçamento comprometido com a aquisição de produtos nos centros urbanos, produtos que antes eram produzidos na propriedade, passando agora a empregar processos de relativa especialização e vendo sua autonomia restringida em favor da ingerência crescente de atores externos no processo produtivo agrícola.

É claro que o rural não sucumbe sem esboçar resistência. De muitas formas as famílias de agricultores continuam a manter um conjunto de práticas e de costumes que evidenciam uma ligação diferenciada com o espaço em que residem e com as tradições que construíram ao longo do tempo. Como bem esclarece Lefebvre (1978), em obra especificamente devotada ao tema aqui explorado, ao tratar da reprodução camponesa nos mais diversos sistemas econômicos:

La comunidad rural se mantiene, se defiende. Desaparece o se reconstituye bajo modos de producción muy diferentes: esclavista, feudal, capitalista, socialista. Persiste, más o menos viva, en ascensión o disolución, desde los tiempos más remotos hasta nuestros días; ciertamente no extraña a las vicisitudes de la Historia y las transformaciones económico-políticas, pero con vida e historia propias (LEFEBVRE, 1978, p. 27).

Espera-se que a análise a seguir encetada sobre as tríades lefèbvrianas possa contribuir para esclarecer a forma e a evolução do pensamento do autor em relação à lógica cidadecampo no seio da sociedade urbana. De forma geral, o que se tentou esboçar aqui, e se 
NORUS - v4, n.6, jul - dez 2016.

pretende aprofundar contiguamente, é que o rural não desapareceu enquanto estrutura espacial e sistema de relações, mas se apresenta hoje extremamente sujeitado pela lógica urbana, expressando ainda muitas dinâmicas diferenciadas, mas não totalmente livres de condicionamentos advindos de expressões da urbanidade.

Como abordado na introdução, a obra de Henri Lefebvre passa ainda por um momento de redescoberta, e muitos dos entendimentos turvos de sua proposta se mantêm apenas temporariamente, o avanço teórico certamente incumbindo-se de dissipá-los. Nesse ponto, é prudente recorrer a Machado (2008), quando o autor lembra a necessidade de um reconhecimento mais pronunciado por parte das representações de esquerda, das organizações estatais e dos pesquisadores nacionais, não só da importância de sua produção teórica para a explicação da realidade coeva, mas também para a instrumentalização com vistas à transformação social.

\section{Os espaços absoluto, abstrato e diferencial}

De modo inverso à tradição positivista de organização de um pensamento binário, a análise espacial de Lefebvre parte essencialmente de tríades, como aquela representada por três espaços: absoluto, abstrato e diferencial. Tais tríades se superpõem umas às outras pelo conteúdo que contêm. Quanto ao espaço absoluto, esse é apresentado como um espaço mais restrito em dimensões, o que permite que seja profundamente conhecido por seus ocupantes. Nesse espaço, a terra detém um papel fundamental, uma vez que o exercício do poder está ligado à posse ou dominação da terra. Segundo Limonad (2003), esse é um espaço com origem na Antiguidade, sendo, por conseguinte, representado pela cidade política e existindo sob a égide da ascendência do rural sobre o urbano. Nas palavras de Lefebvre:

Civique et religieux à la fois, l'espace absolu conserve donc en lui les lignées, familles, relations immédiates, mais transférées à la cité, à l'État politique fondé sur la ville. Les forces socio-politiques qui occupent cet espace ont aussi des implications administratives et militaires: ni les scribes ni les armées ne restent à part. Ceux qui font l'espace (les paysans, les artisans) ne sont pas ceux qui le gèrent en se servant de lui pour organiser la production et la reproduction sociales, à savoir les prêtres, guerriers, scribes, princes. Ceux-ci possèdent l'espace que d'autres produisent, et se l'approprient en jouissance (LEFEBVRE, 2000, p. 59-60, grifos do autor).

Se o espaço absoluto está ligado à origem, à linhagem de consanguinidade e ao poder emanado desta, o absoluto somente cederá espaço quando o capitalismo impuser, gradativamente, um novo modo de vida e de organização em que a abstração e os elementos nela contidos passem a ser a regra, ocupando o lugar dos laços que uniam os indivíduos antes 


\section{A relação entre rural e urbano na ótica de Henri Lefèbvre}

do sistema capitalista. Esse novo espaço consiste no espaço abstrato, o qual surge sem que o absoluto tenha desaparecido totalmente de nossa sociedade - embora restrito a pormenores do cotidiano espacial. A passagem do espaço absoluto ao espaço abstrato se dá somente quando se consegue suplantar o primeiro devido ao alto grau de complexidade dado pelo capitalismo na sua forma de organização econômica, política e social do espaço.

A passagem do espaço absoluto ao espaço abstrato se dá a partir de espaços de acumulação, tanto em sentido econômico e de pilhagem de riquezas introduzido pelo capitalismo, como acumulação de saberes, de tempos, de culturas. $\mathrm{O}$ espaço abstrato que resulta dessa acumulação é o espaço contemporâneo, o qual ocupamos na atualidade, um espaço já constituído a partir da sujeição do rural ao urbano. Trata-se de um espaço intrinsecamente imiscuído com a capacidade do capitalismo de interpor a homogeneidade sem destruir completamente a diversidade precedente.

Na verdade, a ação do capitalismo se dá muito mais no sentido de se apropriar da diversidade local, moldando-a em seu favor. Bravermann (1987) alerta para a centralidade dessa questão quando afirma que: "Como o capitalismo transformou toda a sociedade em um gigantesco mercado é um processo que tem sido pouco estudado, embora constitua uma das chaves para toda a história social recente" (BRAVERMANN, 1987, p. 231). Não obstante, essa estratégia não o impede de agir energicamente na destruição ou transformação daqueles elementos locais que ameacem a lógica de funcionamento do espaço abstrato. Dessa forma, o espaço abstrato é um espaço material, concreto, mas recoberto por abstrações que são produzidas pelo capitalismo e ventiladas nos espaços materiais de modo a serem reproduzidas pelos seres humanos. O ápice da concretude e, ao mesmo tempo, da abstração se chama mercado, palavra-chave do capitalismo para a qual se dirigem atualmente todas as atenções das relações humanas, de trabalho e mesmo os pequenos esforços governamentais de se imiscuírem dessa hegemonia.

Se o espaço abstrato é o espaço da dominação hegemônica do sistema capitalista, há esperança de saída através do espaço diferencial, que surge como uma alternativa ao modelo de homogeneização social preconizado pelo capitalismo. A negação do espaço abstrato implicaria imaginar uma sociedade completamente atomizada, sem subjetividade e apenas cega pela obediência ao grande capital. A permanência de uma sociabilidade camponesa e a existência de laços de reciprocidade ainda muito fortes em diversos espaços rurais são exemplos de espaços diferenciais que resistem na contracorrente da lógica imposta pelo espaço abstrato. O crucial para o entendimento da formação dos espaços abstratos é 
NORUS - v4, n.6, jul - dez 2016.

compreender, como alerta Lefebvre (2000), que os espaços diferenciais surgem justamente do caráter padronizador presente no espaço abstrato, uma vez que essa padronização não consegue jamais atingir a totalidade, acaba por deixar lacunas, nas quais espaços diferenciais surgem como outra via possível. Ao mesmo tempo, essa tentativa de uniformidade espacial nutre naqueles a quem ela é imposta um sentimento de transgressão, que, ao ser exteriorizado, estimula ainda mais a formação de espaços diferenciais (LEFEBVRE, 2000).

Disso tudo, existem ressalvas a serem feitas. A primeira delas torna cogente destacar que os espaços diferenciais não são redutos intocáveis e idílicos. O capitalismo pode e com frequência se apropria desses espaços, adequando-os às suas finalidades. A segunda observação dedica-se a enfatizar que, apesar de vivermos hoje um espaço abstrato permeado por espaços diferenciais, o espaço absoluto não desapareceu. A existência, ainda hoje, de comunidades tradicionais e de diversas sociedades de coletores-caçadores com papel ainda considerável no atendimento de muitas demandas alimentares explicita essa afirmação.

A disseminação do espaço abstrato ocorre em graus diferenciados de acordo com a localização geográfica focalizada, e, quanto maior a penetração do capitalismo em uma dada sociedade, mais abstrato será o seu espaço. Igualmente, quanto menor o avanço das forças capitalistas, mais próxima de um espaço absoluto estará essa sociedade e, ao mesmo tempo, mais marginalizada pelo sistema também estará, devido às poucas chances de sucesso na reprodução da vida contemporânea fora das leis de mercado. Podem-se trazer como exemplo aqueles recônditos planetários onde a hegemonia capitalista ainda não se impôs, relegando tais espaços a uma produção de subsistência e acanhada em fragmentos menores do território, onde a sua reprodução ampliada torna-se inviável.

A última ressalva dirige-se a demonstrar que o espaço diferencial é sim o espaço da diferença, mas não da diferença entendida como desigualdade ou assimetria social. Para esclarecer de forma mais definitiva, é oportuno utilizar as palavras de Limonad:

\footnotetext{
Para o autor, o espaço socialista será um espaço de diferenças. Parece contraditório. No entanto, Lefebvre não está se referindo a desigualdade, mas de uma diferença que está na base de uma praxis sócioespacial, com potencial de mudança social, a luta que procura manter ou resgatar o valor de uso do espaço da tendência em transformá-lo unicamente em valor de troca (LIMONAD, 2003, p. 12-13, grifos da autora).
}

Já se salientou anteriormente que no contexto atual o embate central não se dá mais entre rural e urbano; outra vez é cabível reiterar: não porque o primeiro tenha desaparecido, mas porque se deixou submeter por uma lógica antes emanada do segundo, hoje já difundida globalmente. O embate fundamental da sociedade hodierna trata-se da luta de classes, a qual, 


\section{A relação entre rural e urbano na ótica de Henri Lefèbvre}

como realçado por Lefebvre (2000), é protagonista na produção do espaço, uma vez que as classes envolvidas atuam como agentes produtores do espaço e sujeitos por ele condicionados. Para o autor, a luta de classes se expressa claramente no espaço, sendo a única responsável pelo fato de o espaço abstrato ainda não grassar absoluto sobre o planeta. A luta de classes produz o espaço diferencial, materializando diferenças imanentes e não imanentes ao sistema, respectivamente: as disparidades socioeconômicas e as diferentes possibilidades de gerenciamento do espaço, voltadas para a equidade social economicamente viável e não para a espoliação econômica socialmente insustentável.

\section{As representações do espaço, os espaços de representação e a prática espacial}

Outra tríade sobreposta na análise espacial e proposta por Lefebvre refere-se às representações do espaço, aos espaços de representação e à prática espacial. Como indicado na seção anterior, o espaço abstrato se orienta para a homogeneização; assim, a sociedade capitalista que ele engendra caracteriza-se por desviar-se dos contrastes, do diferente, da alternatividade que se apresenta como opção, buscando sempre o igual, a identidade, mas não uma identidade qualquer, e sim uma identidade construída. Como estratégia para a manutenção dessa igualdade artificial, o capitalismo se vale da reprodução de padrões, comportamentos, estereótipos, modelos, visões de mundo. É assim que o espaço abstrato promove a naturalização de todos os processos e eventos assimétricos e excludentes, de modo a torná-los mais aceitáveis.

Essa naturalização de padrões forjados só é possível por meio de representações do espaço que instituem convenções a serem seguidas e situações a serem aceitas. As representações do espaço, assim, lembram que o espaço não é neutro, não é uma tábula rasa, mas se orienta para a repetição de comportamentos que favorecem determinados grupos sociais. Destarte, é possível afirmar que as representações do espaço estão "liées aux rapports de production, à l' 'ordre' qu'ils imposent et par là, à des connaissances, à des signes, à des codes, à des relations 'frontales' [...]” (LEFEBVRE, 2000, p. 43). Uma dessas ordens emanadas das representações do espaço a que se refere Lefebvre que mais se impõe no contexto hodierno trata-se das leis de mercado, abstração característica do espaço abstrato, que, juntamente com o Estado, molda, limita, direciona e disciplina os seres humanos.

É possível depreender com maior clareza o papel das representações do espaço a partir da análise de Lefebvre (1999a), quando o autor apresenta o entendimento de Marx de que estaríamos vivendo em um mundo invertido e a proposta do marxismo de desfazer essa 
NORUS - v4, n.6, jul - dez 2016.

inversão. O mundo invertido seria caracterizado pela exploração capitalista da burguesia sobre os trabalhadores ou produtores de objetos materiais e abstratos, fazendo da pobreza destes um mecanismo de enriquecimento daqueles. No mundo invertido, a ação do Estado não é dirigida com vistas ao atendimento das necessidades da população, mas sim à manutenção de um status quo que ratifica e mesmo legitima a posição e a ação da classe burguesa. Assim, por meio da visão proletária do marxismo destacada no texto de Löwy (1998) e da missão histórica que Lefebvre (2006) indica caber a essa classe, seria possível colocar em prática o projeto de desestabilização do mundo invertido presente na obra de Marx.

A defesa de uma perspectiva de conhecimento e de uma visão de mundo que prima pelas demandas e pelo reconhecimento da situação social em que se encontra o proletariado representa um caminho de ação para reverter uma inversão social promovida pela lógica capitalista e disseminada pelas representações do espaço. É nesse momento que emergem os espaços de representação, assim definidos por Lefebvre:

Les espaces de représentation, présentant (aven ou sans codage) des symbolismes complexes, liés au côte clandestin et souterrain de la vie sociale, mais aussi à l'art, qui pourrait éventuellement se définir non pas comme code de l'espace mais comme code des espaces de représentation (LEFEBVRE, 2000, p. 43, grifo do autor).

Os espaços de representação são espaços de contestação, de contrariedade à ordem estabelecida pelas representações do espaço decorrentes do sistema capitalista. Os espaços de representação são aqueles em que as relações sociais se desvelam, em que o senso comum artificialmente instituído passa a ser questionado e chega mesmo a ser rompido. Dessa forma, destaca Martins (2004), os espaços de representação também interferem ativamente na produção do espaço, é claro que sua margem de influência é mais restrita do que aquela de que dispõem as representações do espaço, uma vez que estas se constituem enquanto representantes dos atores hegemônicos e os espaços de representação advêm essencialmente das classes espoliadas pela lógica do sistema capitalista. Por conseguinte, pode-se depreender que é por meio dos espaços de representação e da difusão da proposta neles implícita que se abre um caminho para a reversão do mundo invertido.

É no último elemento da tríade, a prática espacial, que os espaços de representação e as representações do espaço se encontram. Segundo Lefebvre (2000), a prática espacial consiste na projeção sobre o espaço da prática social, entendida enquanto o imaginário, os simbolismos e os sentimentos, de forma controlada pela prática política, que envolve o controle estatal. De acordo com o autor, a prática espacial implica concomitantemente na produção de espaços de representação e na reprodução de representações do espaço. Desse 


\section{A relação entre rural e urbano na ótica de Henri Lefèbvre}

modo, as representações do espaço provenientes de uma escala global dirigem-se, de forma gradativa, à dimensão do cotidiano, onde elas podem ser aceitas, assimiladas e reproduzidas como mormente o fazem -, transformando-se, portanto, em prática espacial, ou podem eventualmente ser rejeitadas, podem dar lugar a mecanismos de resistência, nutrindo a formação de possibilidades alternativas, e, do mesmo modo, tem-se, também neste caso, uma prática espacial.

De forma concisa, objetivando sintetizar o acima exposto é possível afirmar que:

A prática espacial de uma sociedade encobre faces do seu espaço, assim como essa mesma prática espacial descobre e decifra o espaço que ela contém. Na sociedade moderna a vida cotidiana na realidade urbana e o próprio emprego do tempo são exemplos de como a prática espacial ocorre e acaba definindo aquele espaço, embora não se mostre totalmente revelado (MARTINS, 2004, p. 31).

Nos espaços rurais, as representações do espaço são oriundas de uma lógica urbana que busca se impor enquanto racionalidade dominante. Sob muitos aspectos, essa tendência ao entendimento da realidade a partir de uma perspectiva urbana se mostra realmente predominante nos espaços rurais, de modo que hoje o ideário dos agricultores familiares se encontra povoado por projetos de aquisição de bens que, dentro de uma antiga racionalidade, seriam percebidos como desnecessários, enquanto atualmente se revelam indispensáveis diante da pressão midiática e dos constrangimentos velados que se instituem dentro da própria comunidade quando da ausência de determinado equipamento ou utensílio doméstico. E é justamente a esse contexto extremamente atual de dependência da agricultura e dos agricultores que se refere Lefebvre: "Hoy día la vida campesina carece de autonomía. No puede evolucionar de acuerdo con leyes propias: se relaciona de muchas maneras con la economía general, la vida nacional, la vida urbana, la tecnología moderna..." (LEFEBVRE, 1978, p. 37).

Não obstante, espaços de representação são continuamente produzidos, a manutenção de uma relativa autonomia por parte das famílias de agricultores, por meio da prática do autoconsumo e da manutenção da propriedade legal da terra, a existência de uma relação diferenciada com a natureza e de relações interpessoais ainda mais solidárias que no urbano são outros exemplos de espaços de representação cultivados no campo. Desse modo, conforma-se uma prática espacial fundamentalmente condicionada pelo urbano, mas ainda povoada por diferenciações que, apesar de menos intensas e determinantes do que no passado, são ainda fundamentais para a caracterização dos espaços rurais e da racionalidade sob a qual operam aqueles que lá residem. 
NORUS - v4, n.6, jul - dez 2016.

Nesse sentido, parece adequado retomar uma vez mais a ideia que se delineia como o fio condutor do pensamento de Lefebvre (1978), que aqui se buscou modestamente explicitar: o avanço da urbanização e da lógica subjacente a esse processo não implica na extinção sumária de formas anteriores de organização, mas sim no remodelamento dessas formas, na sua reconfiguração, em um processo que mescla o abandono de certos valores, mas também a continuidade e a reprodução de muitos outros, caracterizando um amálgama de resistência e sujeição. Fenômeno análogo ocorre com o próprio capitalismo, muitos autores já se dedicaram a estudar como esse sistema não só mantém, como se aproveita economicamente de formas de produção não capitalistas, como a produção agrícola camponesa. É oportuno encaminhar o fim do presente trabalho com as palavras do próprio autor: "El tejido urbano no impide la persistencia de antiguos núcleos. Son centros de vida urbana transformados, renovados [...] que, transformándose, se ha mantenido” (LEFEBVRE, 1978, p. 217).

\section{Conclusão}

Existem ainda muitas questões a serem discutidas e ampliadas no que tange à obra de Henri Lefebvre, especialmente nos aspectos relacionados à relação rural-urbano. Este artigo traz mais uma contribuição nesse aspecto, ao evidenciar duas tríades no pensamento de Henri Lefebvre e seus desdobramentos concernentes às análises do rural e do urbano. De modo geral, objetivou-se uma exposição breve da compreensão de Lefebvre sobre como se relacionam os espaços rurais e urbanos, desmistificando possíveis depreensões equivocadas. Assim, cabe aqui, pela derradeira ocasião deste trabalho, destacar que não existe na obra de Lefebvre nenhuma previsão terminal sobre o rural, mas sim um entendimento de que estes espaços se encontram cada vez mais submetidos aos imperativos e lógicas advindos do urbano.

Talvez seja cabível relacionar o entendimento de Lefebvre com as abordagens marxistas clássicas sobre o fim do campesinato. No contexto atual é possível verificar de forma patente que a agricultura baseada no trabalho familiar não desapareceu ou mesmo se encontra em processo de desaparecimento, apresentando-se ainda muito importante para o atendimento das demandas alimentares mundiais e para o emprego da população no campo. Mas isso não implica na constatação de um erro nas análises marxistas, pois, de muitas formas, o campesinato tal como esses autores o conheceram já não existe mais na atualidade. O camponês completamente autônomo, desconectado dos mercados, dependente apenas de relações localmente estabelecidas e representante de um modo de vida diametralmente oposto 


\section{A relação entre rural e urbano na ótica de Henri Lefèbvre}

ao dos espaços urbanos certamente já esvaeceu. Mas isso não significa que agricultura baseada no trabalho familiar tenha desaparecido; de modo inverso, ela desenvolveu estratégias diversificadas com o intuito de compor os mercados modernos.

De certa forma, e é isso que a análise de Lefebvre pretende mostrar, o rural na perspectiva idealizada de um espaço exclusivamente guiado por lógicas internas, funcionando em outro tempo, com agentes com racionalidades absolutamente contrastantes com a dos espaços urbanos, já deixou de existir, e retomá-lo - se em algum momento pareceu ser a intencionalidade destas laudas - não é um caminho para a construção de espaços mais equânimes, tampouco representa um processo de avanço das relações socioprodutivas. Não se trata aqui de propor a ruralização da sociedade em oposição à ideia de urbanização defendida por Lefebvre. Mas sim de demonstrar a importância de valores e propostas que emergem do campo como alternativas aos modelos dominantes. É claro que não são os únicos valores e propostas, nem mesmo sugere-se que sejam os mais relevantes para a formação de espaços diferenciais, são apenas possibilidades que expressam perspectivas diferenciadas de apreensão da realidade, nas palavras de Lefebvre, são somente espaços de representação, em que as representações do espaço são questionadas e nos quais novos caminhos se delineiam.

\section{Referências}

BRAVERMAN, Harry. Trabalho e capital monopolista: a degradação do trabalho no século XX. 3. ed. Rio de Janeiro: LTC, 1983.

FONTOURA, Luiz Fernando Mazzini. Campo, cidade e a natureza recriada na artificialidade urbana. Boletim Gaúcho de Geografia, Porto Alegre, n. 36, p. 43-51, 2011.

LEFEBVRE, Henri. A crítica da economia política. In: LEFEBVRE, Henri. A cidade do capital. Rio de Janeiro: DP\&A, 1999a. p. 75-114.

LEFEBVRE, Henri. A revolução urbana. Belo Horizonte: Ed. UFMG, 1999 b.

LEFEBVRE, Henri. De lo rural a lo urbano. 4. ed. Barcelona: Ediciones Península, 1978.

LEFEBVRE, Henri. La production de l'espace. 4. ed. Paris: Anthropos, 2000.

LEFEBVRE, Henri. O direito à cidade. 4. ed. São Paulo: Centauro, 2006..

LIMONAD, Ester; LIMA, Ivaldo Gonçalves de. Entre a ordem próxima e a ordem distante: contribuições a partir da obra de Henri Lefebvre. In: Encontro Nacional da Anpur, 10., Niterói, 2003. Anais... Niterói: UFF/GECEL, 2003. p. 15-33.

LÖWY, Michael. Ideologia e ciência segundo Marx. In: LÖWY, Michael. As aventuras de Karl Marx contra o Barão de Münchhausen. 6. ed. São Paulo: Cortez, 1998. p. 99-114. 
NORUS - v4, n.6, jul - dez 2016.

MACHADO, Carlos Roberto. Momentos da obra de Henri Lefebvre: uma apresentação. Ambiente \& Educação, Rio Grande, v. 13, n. 1, p. 83-95, 2008.

MARTINS, Solismar Fraga. A produção do espaço em uma cidade portuária industrial: O caso do município do Rio Grande/RS. Tese de Doutorado em Geografia - Centro de Filosofia e Ciências Humanas, Universidade Federal de Santa Catarina, Florianópolis, 2004. 